Research Article

\title{
Study on Explosion-Resistance of Biomimetic Layered Honeycomb Structure
}

\author{
Ji Li, Shaoqing Shi $\mathbb{i}$, Weiming Luo $\mathbb{1}$, and Qifan Wang \\ Department of Civil Engineering, Army Logistics University of PLA, Chongqing 401311, China \\ Correspondence should be addressed to Shaoqing Shi; ssq601@163.com
}

Received 15 July 2019; Accepted 14 November 2019; Published 19 February 2020

Academic Editor: Evangelos J. Sapountzakis

Copyright (C) $2020 \mathrm{Ji} \mathrm{Li} \mathrm{et} \mathrm{al.} \mathrm{This} \mathrm{is} \mathrm{an} \mathrm{open} \mathrm{access} \mathrm{article} \mathrm{distributed} \mathrm{under} \mathrm{the} \mathrm{Creative} \mathrm{Commons} \mathrm{Attribution} \mathrm{License,} \mathrm{which}$ permits unrestricted use, distribution, and reproduction in any medium, provided the original work is properly cited.

\begin{abstract}
A new type of explosion-resistant biomimetic layered honeycomb structure was designed based on the natural mechanism and biological inspiration, which was mainly composed of a sacrificial layer and a bearing layer. The shock tube device was adopted to analyze the dynamic response of the biomimetic layered honeycomb structure under the action of explosion load in order to obtain the deformation modality, deflection data, and strain time-history curve of the structure. It turns out that the maximum deformation deflection of the back panel of the structure is only $28 \mathrm{~mm}$. Compared with the structure of single-layer honeycomb, the independent sacrificial layer, and bearing layer, the biomimetic layered honeycomb structure has good explosion-resistant performance and can repeatedly bear multiple explosion loads. Besides, equivalent homogenization theory was employed to carry out numerical simulation. The results show that the numerical simulation results are perfectly in line with the results of experiments, and the numerical simulation method is proven to be feasible and effective. Under the action of explosion load, the biomimetic layered honeycomb structure absorbs energy mainly by sacrificial layers that are in layered and staggered arrangement. In addition, the sharp rangeability of the kinetic energy of bearing layer structure indicates that it has the feature of large mass, which can be used as the bearing part of the biomimetic layered honeycomb structure.
\end{abstract}

\section{Introduction}

Explosive terrorist attack is one of the major threats to social public safety; therefore, how to develop an explosion-resistant structure with good performance is the main concern for researchers. Explosion-resistant structure can absorb the explosive shock wave and prevent buildings and personnel from being seriously hit. Aluminum honeycomb structure is widely used as explosion-resistant structure for its high specific strength, high specific stiffness, and good energy absorption ability $[1,2]$.

Dharmasena et al. [3] studied the dynamic mechanical response of square honeycomb plate in explosion test and compared the square honeycomb plate with the solid core plate with equal density, and it was then found that the deflection of square honeycomb plate is smaller than that of solid core plate. Deng et al. [4] obtained the optimal relative density of the honeycomb plate under explosion load through numerical simulation, and it was found that the sandwich layer of honeycomb absorbed most of the energy and played a protective role in the panel. Yang et al. [5] used AUTODYN to numerically simulate the explosion-resistance of aluminum honeycomb structure and found that the thickness of panel and the height of the sandwich layer of honeycomb have obvious influence on the deformationresistance ability of aluminum honeycomb structure. Nurick et al. [6] and Karagiozova et al. [7] studied the inelastic response of the composite structure composed of low carbon steel plate and aluminum honeycomb under explosion through experiment and numerical simulation. It turned out that the explosion shock wave formed an even pressure after propagating through the tube, which caused even crush failure to the specimen, with no local damage. Shen et al. [8] conducted an explosion test to the interlayer panel of aluminum honeycomb and concluded that the explosion intensity, thickness of interlayer, and thickness of panel are the main parameters to determine deformation deflection. Zhang et al. [9, 10] studied the dynamic response of 
aluminum honeycomb sandwich structure under four kinds of TNT explosive equivalents, and the results showed that the energy absorption performance of aluminum honeycomb sandwich panel is excellent. Li et al. [11] carried out a close-range explosion test on aluminum honeycomb sandwich structure and found that the deformation and failure model of the panel could be largely affected by the explosion distance: short distance could lead to indentation and damage, while long distance could result in obvious plastic deformation.

The "Global Hawk" unmanned aerial vehicle (UAV) is a high-speed UAV integrated with the most advanced science and technology, capable of carrying out all-weather and wide-range reconnaissance missions. According to the recently reported wreckage of the downed "Global Hawk" UAV (Figure 1(a)), the internal structure of UAV wing was a biomimetic honeycomb structure. Using biomimetic honeycomb structure as the main component of UAV wing can reduce its self-weight and manufacturing cost. Besides, the biomimetic honeycomb structure of the wing has the characteristics of resisting the impact of heavy objects and birds. In this paper, biological inspiration and image ground for the design of a new explosion-resistant structure were obtained from the bionic mechanism, geometric space, and mechanical properties of the natural honeycomb structure (Figure 1(b)), the forewing of beetles (Figure 1(c)), and natural shell pearl layer (Figure 1(d)) [12-14]. The explosion-resistant biomimetic layered honeycomb structure was therefore proposed. The natural honeycomb structure and the beetle's front wing are all made up of hexagonal units, which have high structural density and large usable space. The new explosion-resistant structure similar to honeycomb on the plane is the most economical and reliable space structure. Inspired by natural shell pearl layer, the explosion-resistant honeycomb structure is proposed to be biomimetic layered. Shell pearl layer is a kind of natural layered structure material. In the shell pearl layer, aragonite content is as high as $99 \%$, and less than $1 \%$ of the rest is mainly protein based organic matter. It is formed by regular arrangement of polygonal aragonite chips. There is a very thin layer of organic matter between the chips. When impacted by external forces, the cracks on the surface chips will not spread to other chip layers but will deflect when they extend to the organic matter combined between the layers. Therefore, in the design of explosion-resistant honeycomb structure, the idea of biomimetic layered structure is introduced to achieve good mechanical properties of honeycomb structure.

The explosion test of shock tube on biomimetic layered honeycomb structure was carried out, and its explosionresistant property was then analyzed. In order to verify the feasibility and effectiveness of numerical simulation method, a numerical simulation study was implemented to conduct a comparative analysis on the failure deformation phenomenon between the test and the numerical simulation and a coincidence analysis on strain time-history curve between these two.

\section{Biomimetic Layered Honeycomb Structure}

2.1. Structure Design. The authors, inspired by the internal structure of honeycomb and the forewing of beetle on the basis of bionic mechanism, proposed an explosion-resistant biomimetic layered honeycomb structure, which is mainly composed of a sacrificial layer and a bearing layer, as shown in Figure 2.

Palanivelu et al. [15] designed an explosion-resistant sacrificial layer structure in layered and staggered arrangement combined by recyclable metal cans (Figure 3(a)) and studied the plastic deformation energy and energy absorption property of the sacrificial layer under the action of explosion. It was found that the sacrificial layer structure in layered and staggered arrangement can effectively resist the power of explosion shock wave under the action of explosion and, at the same time, better protect the concrete beam below (Figure 3(b)). Sun et al. [16] proposed a sacrificial layer in layered and staggered arrangement to resist the penetration of projectile body (Figure 3(c)). Each of its layers is a honeycomb structure and arranged in stagger. As shown in Figure 3(c), the sacrificial layer in layered and staggered arrangement consumes energy through its own failure and deformation to protect the concrete structure below when the projectile body penetrates. Inspired by the modal of layered and staggered arrangement, the honeycomb structure with sacrificial layer in this paper also applies a layered and staggered modal, as shown in Figure 3(d). When subjected to explosion shock wave or fragment impact, the sacrificial layer, relying on the characteristics of layered and staggered arrangement and plastic deformation, ensures that the energy and stress transferred to bearing layer are in the critical range of failure, so as to achieve a good protective effect.

The bearing layer consists of an enhanced honeycomb structure, as shown in Figure 4, which is enhanced by filler (sand filling). When subjected to explosive shock wave or fragment impact, the bearing layer is mainly responsible for bearing out-of-plane pressure and bending moment. When a certain deformation is reached, the bearing layer is subjected to in-plane shear and compression.

2.2. Standard of Impact-Resistance under Explosion. If the material is not sensitive to strain rate, biomimetic layered honeycomb structure can be equivalently subject to the impact of an object with initial velocity of $v_{0}$ and mass of $m$ under the explosion load. Therefore, the energy absorption ability of the structure against explosion can be evaluated by the impact-resistant standard.

Four physical indexes are used to determine the impactresistance of biomimetic layered honeycomb structure. The first index refers to the specific energy absorption rate (SEA), which is used to estimate the energy absorption ability of the biomimetic layered honeycomb structure and is defined as the ratio of the total energy (EA) to the structural mass $(M)$ :

$$
\mathrm{SEA}=\frac{\mathrm{EA}}{M}
$$




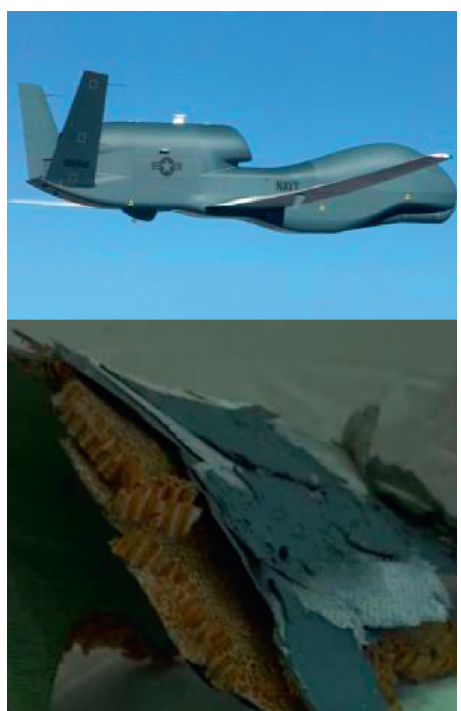

(a)

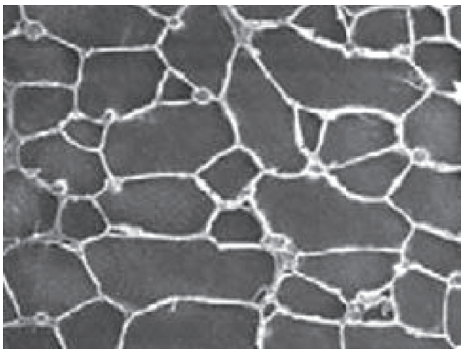

(c)

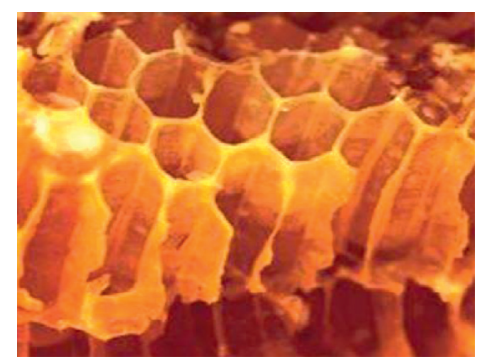

(b)

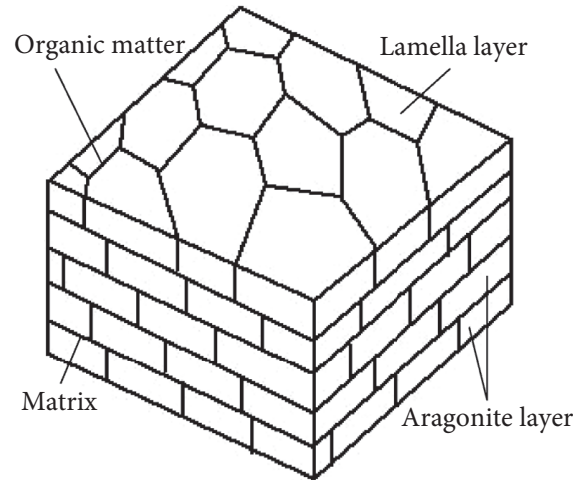

(d)

FiguRe 1: Inspiration from creatures.

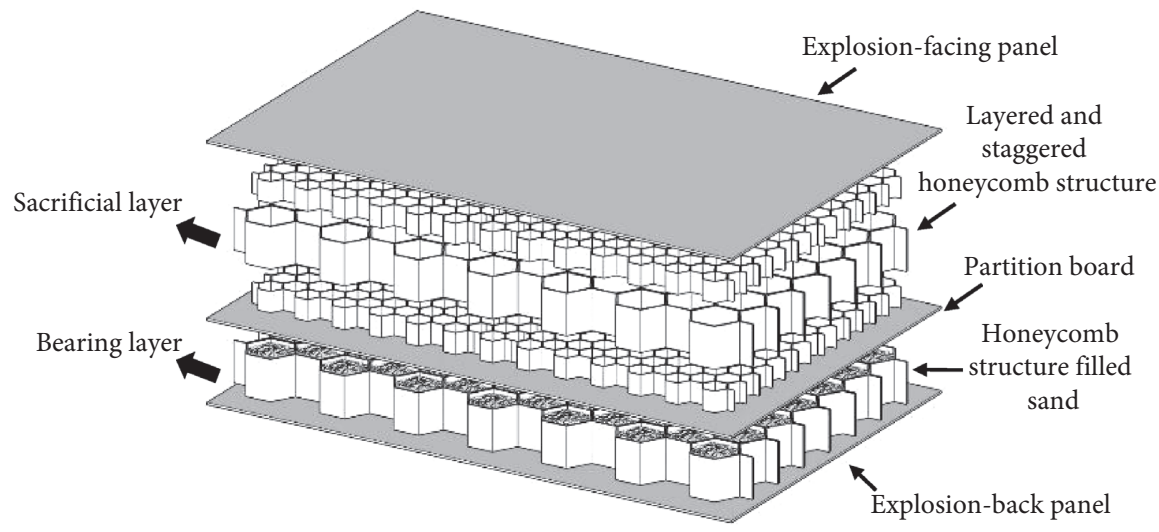

Figure 2: Schematic diagram of biomimetic layered honeycomb structure.

The area enveloped by the force-displacement curve represents the total energy (EA):

$$
\mathrm{EA}=\int_{0}^{d} F(x) \mathrm{d} x
$$

where $d$ is the axial deformation displacement and $F$ is the axial deformation force.

For the biomimetic layered honeycomb structure, the average impact force MF under given axial deformation can be summarized as follows: 


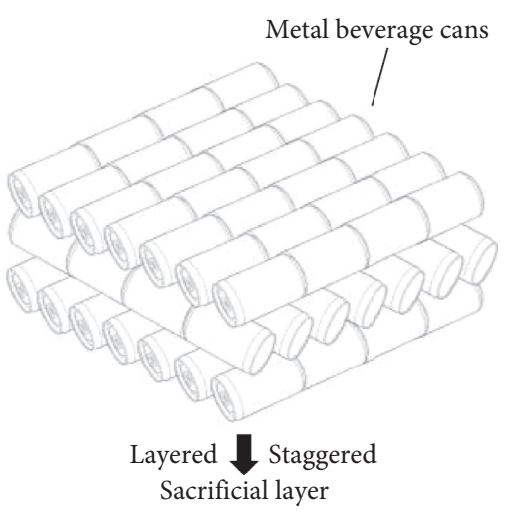

(a)

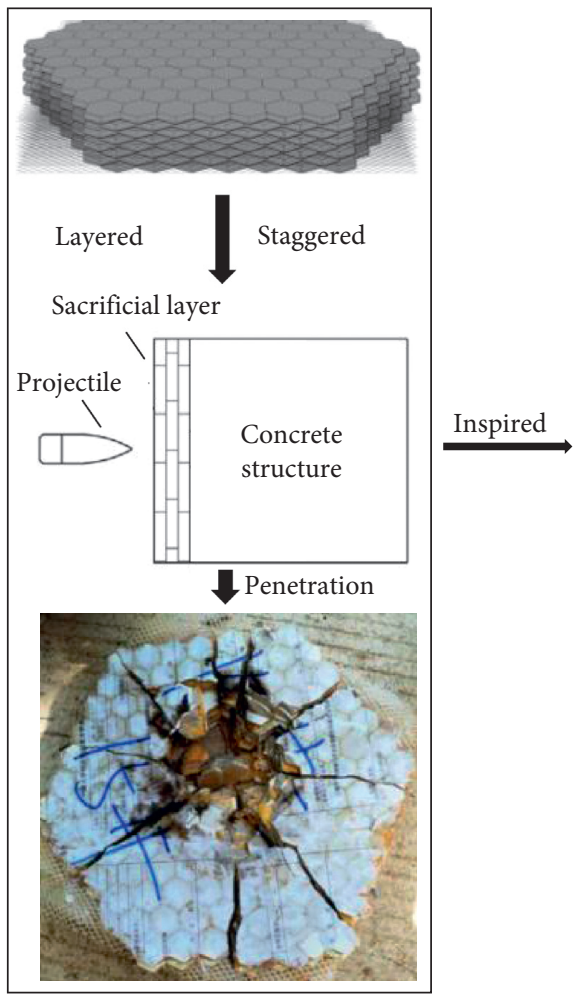

(c)

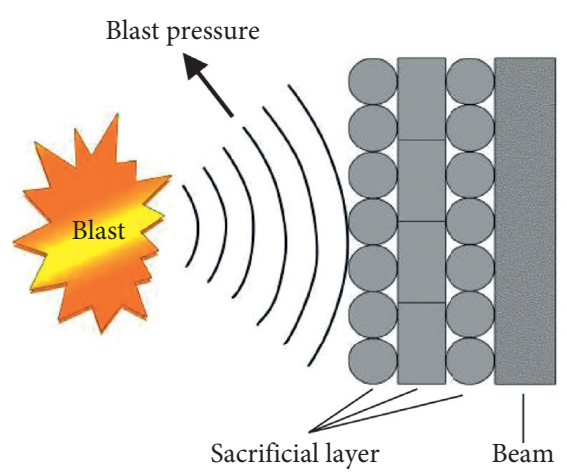

(b)

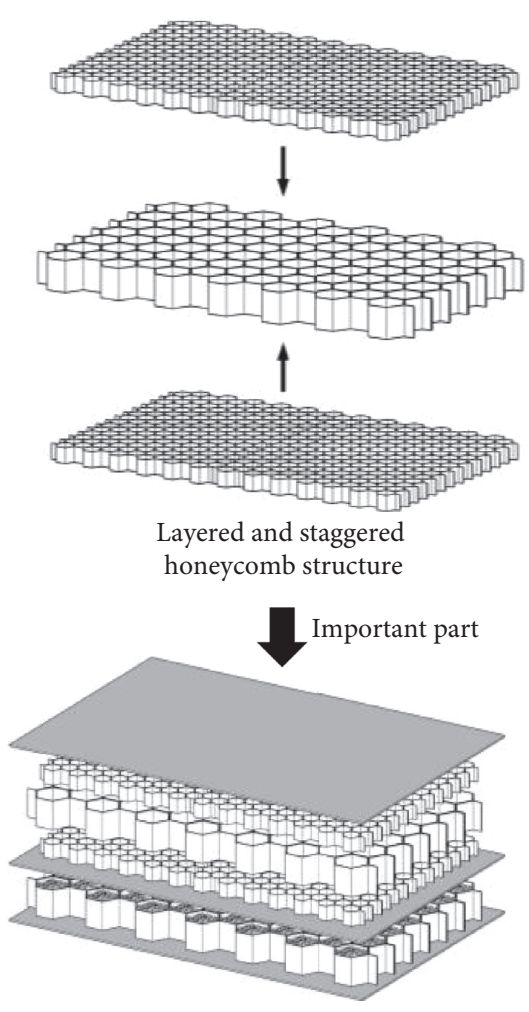

(d)

Figure 3: Design plans for sacrificial layer structure.

$$
\mathrm{MF}=\frac{\mathrm{EA}}{d}
$$

The ratio $C$ of the average impact force MF to the peak impact force $\mathrm{PF}$ in the force-displacement curve under axial impact can be summarized as follows:

$$
C=\frac{\mathrm{MF}}{\mathrm{PF}} \times 100 \% \text {, }
$$

where the ratio $C$ represents the maximum impact-resistance efficiency of the biomimetic layered honeycomb structure.

\section{Test Device and Method}

The shock tube device of a laboratory was used to carry out the explosion test on biomimetic layered honeycomb structure. As shown in Figures 5(a) and 5(b), the total length of the shock tube is $39 \mathrm{~m}$, the inner diameter of the test section is $1 \mathrm{~m}$, and the maximum overpressure of the driving section can reach 10.3 $\mathrm{MPa}$. In the shock tube, the explosion shock wave is produced by filling the cylindrical tube with high-pressure driving gas. When the air pressure in highpressure area is greater than the rupture resistance of 


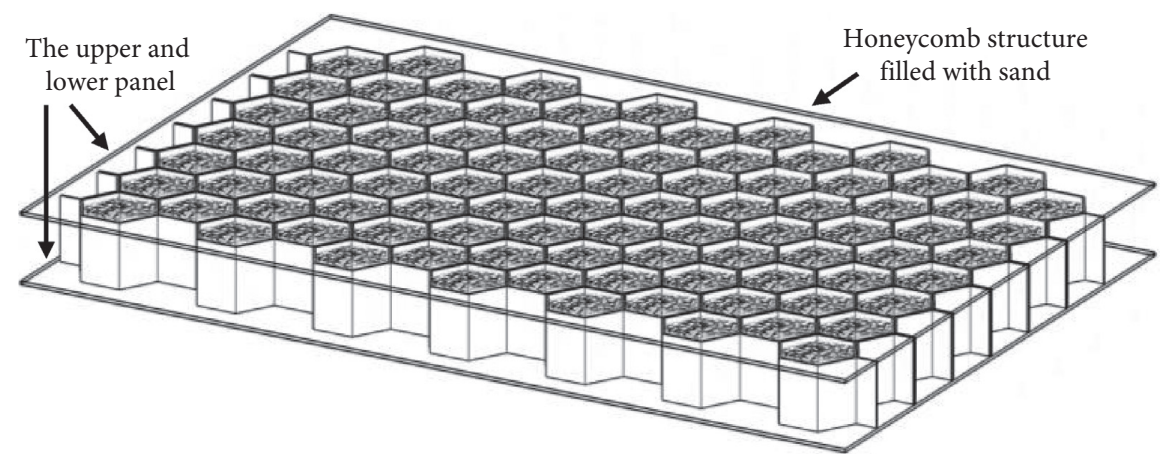

FIgURE 4: Schematic diagram of bearing layer.

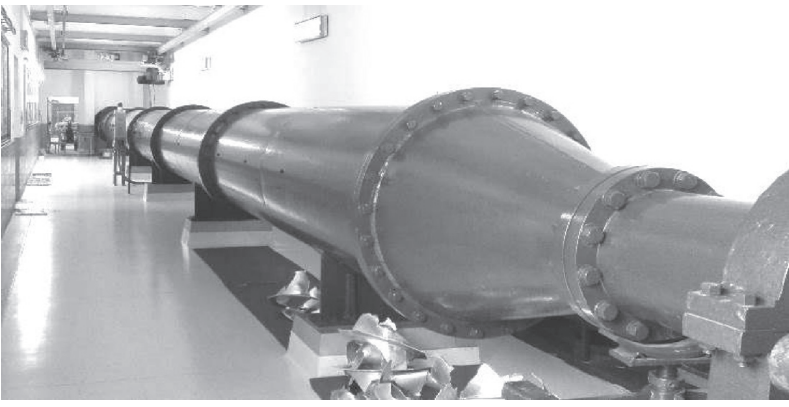

(a)

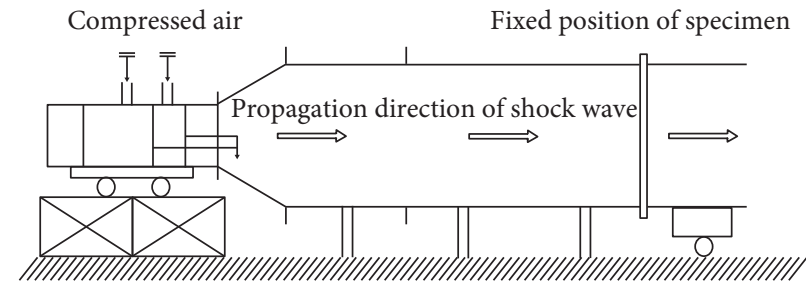

(b)

FIgURE 5: Shock tube device. (a) Real shot. (b) Schematic diagram.

diaphragm, the compressed gas moves rapidly to the lowpressure area to form the explosion shock wave.

In order to avoid test error caused by the streaming effect of explosion shock wave, the specimen placement box is sealed by a stationary fixture with a size of $600 \mathrm{~mm} \times$ $400 \mathrm{~mm} \times 100 \mathrm{~mm}$, as shown in Figures 6(a) and 6(b). The assembly effect is shown in Figure 6(c).

In order to analyze the test data, strain time-history curve of the specimen is recorded by arranging strain collection points. Two groups of radial and longitudinal strain gauges on the back of the specimen are arranged, as shown in Figure 7 . The first group of strain gauges is located in the center of the specimen, because it is considered that large deformation and damage under the explosion will occur in the center of the specimen. The specimen is divided into four parts, and another group of strain gauges is arranged in the center of one part, which also represents the center of the other three parts. The strain time-history curves recorded by two groups of strain gauges are accurate and representative. The bonding position of the strain gauge is on $m=$ $300 \pm 2 \mathrm{~cm} ; n=200 \pm 2 \mathrm{~cm} ; p=150 \pm 2 \mathrm{~cm} ; q=300 \pm 2 \mathrm{~cm}$, and GP represents the strain collection point (Gauge Point). For the specimen with failure deformation, the deflection is measured and recorded along the central axis of specimen in Figure 8.

\section{Test Results and Analysis}

Shock tube explosion test is carried out on the biomimetic layered honeycomb structure (Figure 9(a)). As a comparison, the same tests are also conducted on the single-layer honeycomb structure (Figure 9(b)), the sacrificial layer structure (Figure $9(\mathrm{c})$ ), and the bearing layer structure (Figure $9(\mathrm{~d})$ ), as shown in Table 1.

Explosion tests are carried out, respectively, on the four working conditions under the same level of explosion shock wave. Figure 10 shows a typical pressure time-history curve of explosion shock wave. The shock wave generated in shock tube has the general characteristics of explosive shock wave, that is, containing positive pressure stage and negative pressure stage. Due to the long length of shock tube, the incident explosion shock wave load can be regarded as plane wave pressure load.

As shown in Figures 11(a) and 11(b), the deformation degree of ST1 is large, and there are large folds in the middle of the upper and lower edges of the specimen, forcing the whole specimen to be sunken inward, and the deformation in the central area of specimen is the most serious. Observed from the oblique side, as shown in Figure 12, the failure and deformation state of the whole specimen is "arch." The deformation deflection in the central area of the specimen is the largest, and the maximum deflection degree of the explosion-facing panel is $74 \mathrm{~mm}$, while that of the explosionback panel is $78 \mathrm{~mm}$. The distance between the explosionfacing panel and explosion-back panel is very close in the center of specimen, indicating that damage of the internal honeycomb structure at the central position is the most serious. Results show that severe deformation under the action of explosion occurs in single-layer honeycomb structure; the deformation deflection of the panel is large, the 


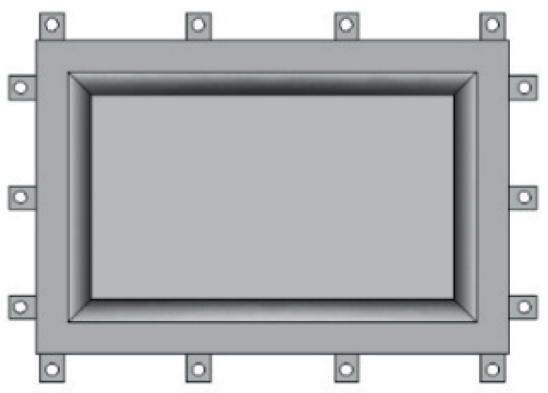

(a)

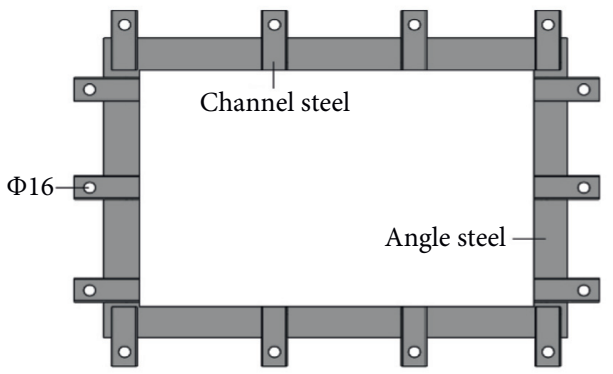

(b)

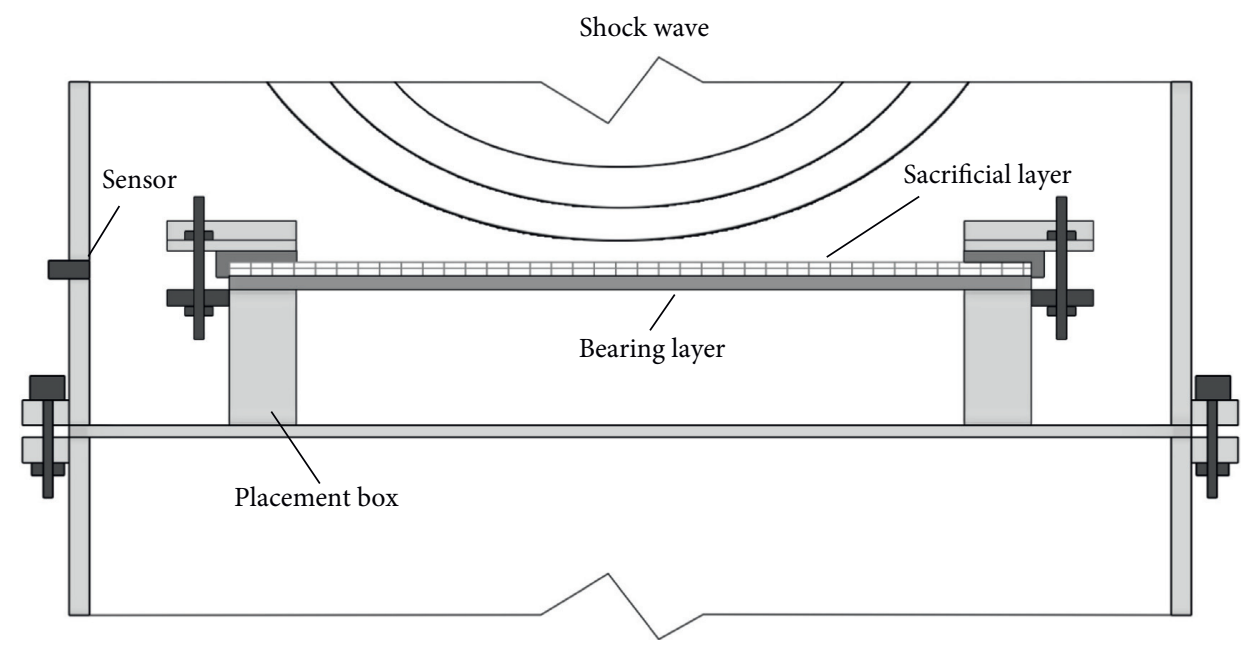

(c)

FIGURE 6: Schematic diagram of specimen assembly. (a) Schematic diagram of placement box. (b) Schematic diagram of stationary fixture. (c) Schematic diagram of assembly effect.

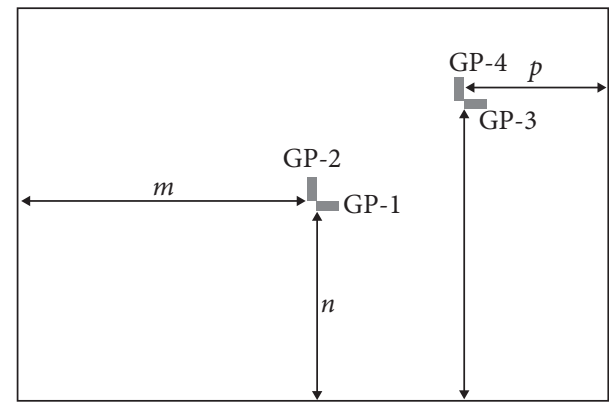

FIgURE 7: Arrangement of strain gauge.

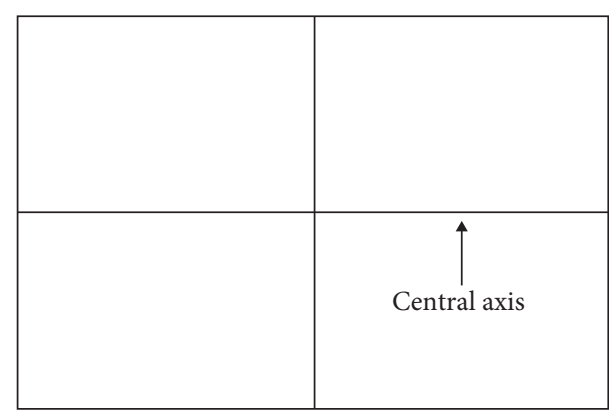

Figure 8: Schematic diagram of central axis in specimen. damage of the internal honeycomb structure is serious, and the whole structure loses the ability to resist explosion.

As shown in Figure 13, strain time-history curves of four GPs in ST1 are recorded in explosion test. It is found that the peak strain of GP-1, GP-3, and GP-4 is larger, among which the peak strain of GP-1 is close to 10000 , indicating that ST1 has a large deformation in the process of explosion-resistance. After reaching the peak strain, the strain of GP-1 decreases greatly, whereas the residual strain is close to that of GP-2, in the range of 2000 4000. The attenuation amplitude of the strain time-history curve of GP-3 and GP-4 is small. Their residual strains are larger, in the range of 6000 to 8000. Severe failure and deformation occurred on ST1 in the process of explosion-resistance, and the final deformation is large.

As shown in Figures 14 and 15, the overall deformation degree of ST2 is small, and there are few folds on the upper and lower edges of the specimen. Deformation deflection of the specimen is small: the maximum deflection of the explosion-facing panel is $15 \mathrm{~mm}$, and the maximum deflection of the explosion-back panel is $24 \mathrm{~mm}$. The amount of compression of the honeycomb structure inside the specimen is small, without serious damage, which shows that the honeycomb structure has the ability to repeatedly resist explosion. The experimental results show that, reinforced by 


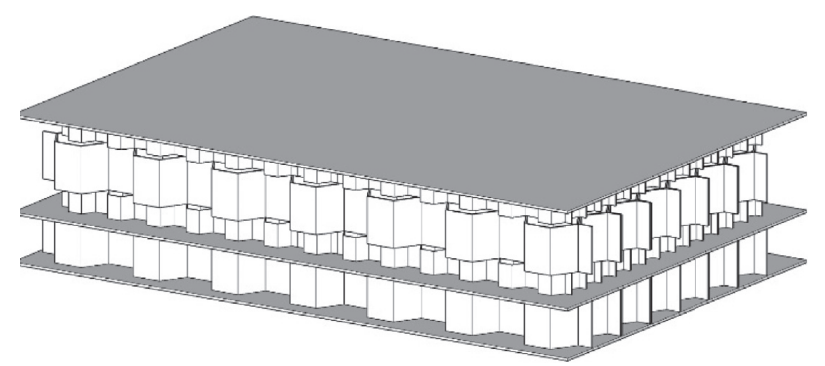

(a)

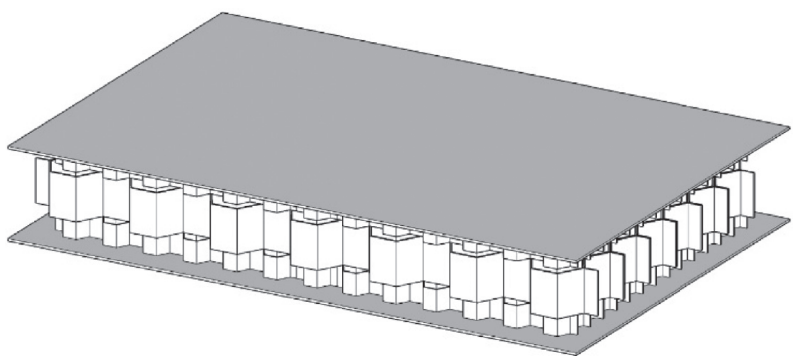

(c)

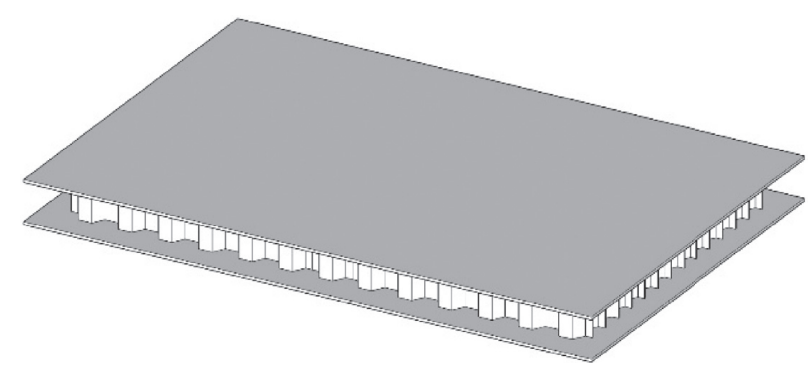

(b)

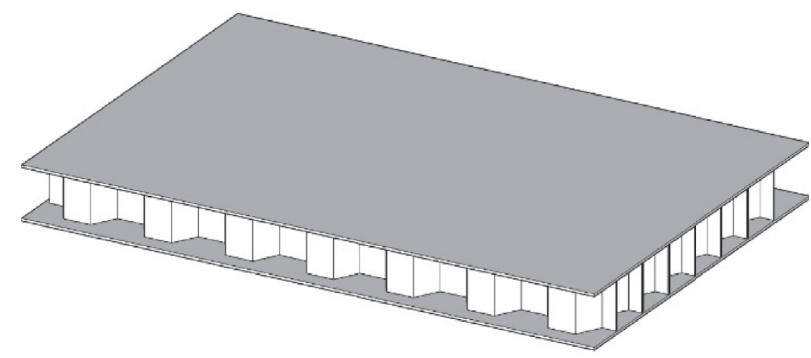

(d)

Figure 9: Schematic diagram of different specimens. (a) Biomimetic layered honeycomb structure. (b) Single-layer honeycomb structure. (c) Sacrificial layer structure. (d) Bearing layer structure.

TABLE 1: Groups of simulated explosion test on shock tube.

\begin{tabular}{lccc}
\hline $\begin{array}{l}\text { Specimen } \\
\text { number }\end{array}$ & Details of working condition & $\begin{array}{c}\text { Structural properties } \\
\text { Thickness/ } \\
\text { mm }\end{array}$ \\
\hline ST1 & Aluminum honeycomb plate & $\begin{array}{c}\text { Single-layer honeycomb } \\
\text { structure }\end{array}$ \\
ST2 & Enhanced aluminum honeycomb plate & Bearing layer structure \\
ST3 & Honeycomb structure in layered and staggered arrangement & 7 & Sacrificial layer structure \\
ST4 & Honeycomb structure in layered and staggered arrangement +enhanced & Biometic layered \\
honeycomb structure & 22 \\
\hline
\end{tabular}

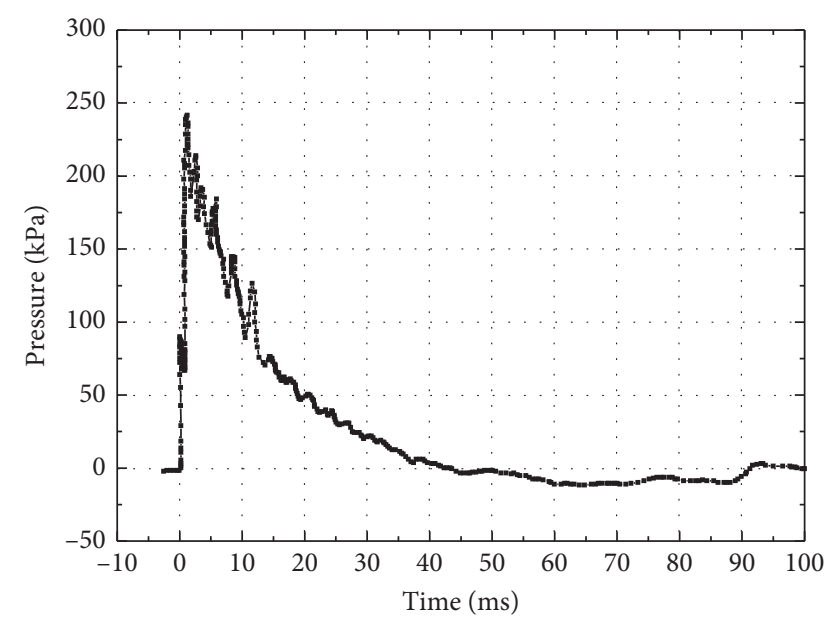

FIgURE 10: Pressure time-history curve of explosion shock wave.

filling sand, the deformation of bearing layer structure is small and has good explosion-resistant ability, which can be used as the bearing part of the biomimetic layered honeycomb structure.
As shown in Figure 16, the peak strain at the four GPs in ST2 is clearly close, in the range of 3000 5000. The residual strains of the four GPs are quite different to a certain extent, but the attenuation laws of the four strain time-history curves are close to each other. The experimental results show that ST2, as a bearing layer structure, has a certain overall deformation in the process of explosion-resistance, and there is no prominent local failure deformation.

Under the action of explosion, ST3, as a sacrificial layer structure, consumes the explosion energy through its own failure and deformation. As shown in Figure 17, the specimen as a whole has a large deformation, with the explosion-facing panel being sunken inward and the explosion-back panel forming an "arch" outward. As can be seen in Figure 18, the maximum deflection of explosion-facing panel is $110 \mathrm{~mm}$, and that of explosion-back panel is $125 \mathrm{~mm}$. Honeycomb structure in layered and staggered arrangement in the central area of the specimen is not completely compressed and damaged and thus can continue to absorb more energy. Compared with ST1, ST3 is more suitable for serving as a sacrificial layer structure to absorb energy and protect the bearing layer structure below. Under the action of the same energy level, the deformation of ST1 is larger, and its energy 


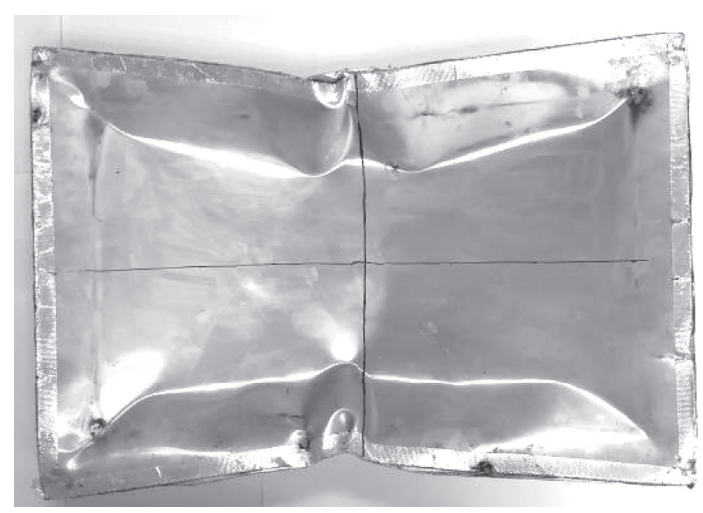

(a)

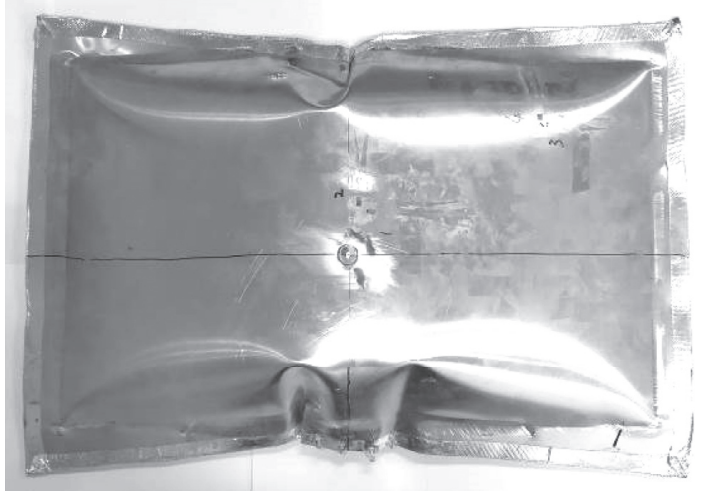

(b)

Figure 11: Front view of ST1 deformation. (a) Explosion-facing panel. (b) Explosion-back panel.

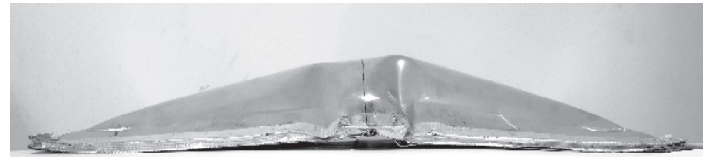

(a)

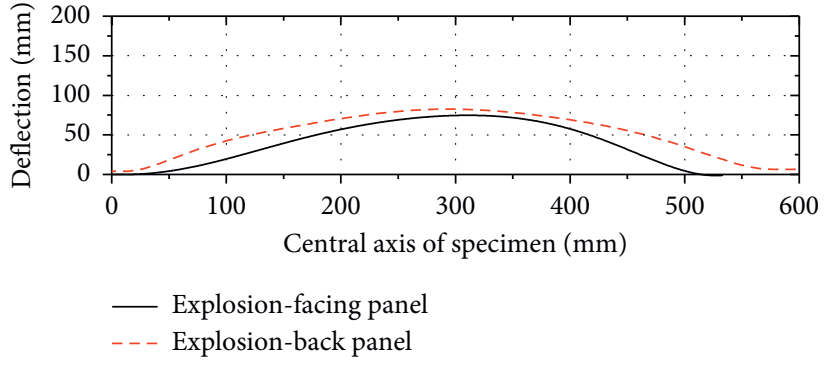

(b)

FIGURE 12: Side deformation and deflection of ST1. (a) Side view of ST1 deformation. (b) ST1 deflection data curve.

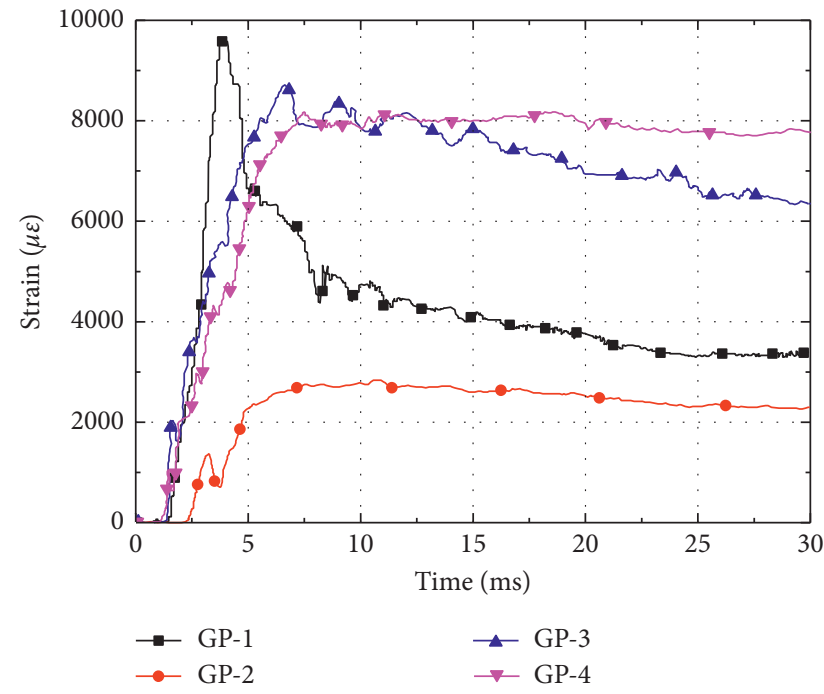

FIGURE 13: Strain time-history curve of ST1 collection point.

absorption is less, while its transmitted energy is more than that of ST3.

After explosion test, the strain time-history curves of ST3's three GPs were recorded, as shown in Figure 19. The peak strain ranges of the three GPs are 2000 10000. After reaching the peak strain, the strain attenuations of the three GPs are all not obvious and have large residual strains. It is shown that ST3 has good energy absorption ability, strong toughness, and strong deformation ability when subjected to explosion load, so it is suitable for serving as a sacrificial layer structure.

The explosion test on ST4 is carried out as shown in Figure 20. It can be found that the specimen has a uniform deformation as a whole with no obvious local failure. It can be concluded from Figure 21 that the maximum deflection of explosion-facing panel is only $6 \mathrm{~mm}$, and the maximum deflection of the explosion-back panel is $28 \mathrm{~mm}$. The bearing layer structure inside the specimen is less affected by the explosion, while the sacrificial layer structure has plastic deformation and dissipates the main explosive energy. Under the action of explosion load, layered biomimetic honeycomb structure reveals good overall performance and has the ability to withstand multiple explosion loads.

By observing the strain time-history curves of the four collection points of ST4 in Figure 22, it can be found that the peak strains of the four collection points are in the range of 2000 3000. Compared with ST1, ST2, and ST3, the fluctuation range of ST4's peak strain is the smallest, indicating that the integrity of ST4 is the best under the action of explosion load. The residual strains of the four collection points are in the range of 250 1750, demonstrating that ST4 has the strongest failure-and-deformation-resistant ability under the explosion load with the same energy level, and it can be reused many times. 


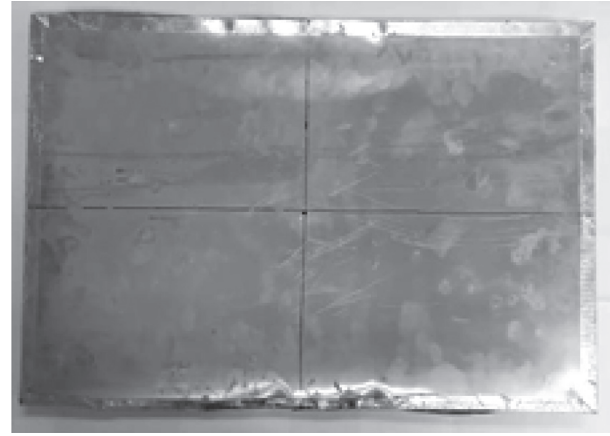

(a)

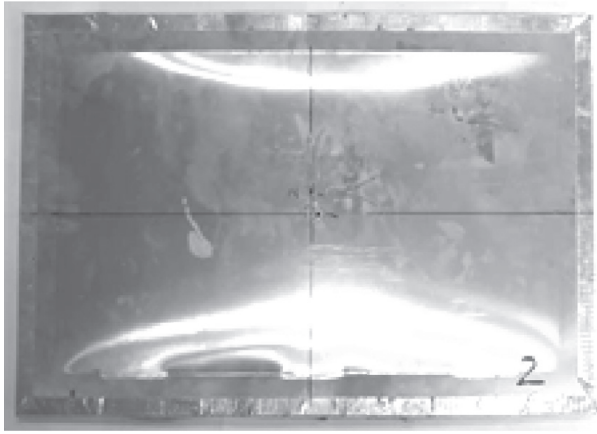

(b)

Figure 14: Front view of ST2 deformation. (a) Explosion-facing panel. (b) Explosion-back panel.

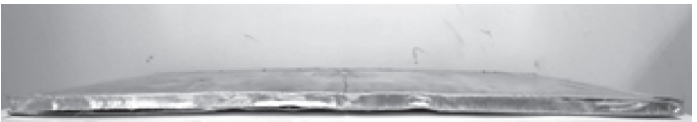

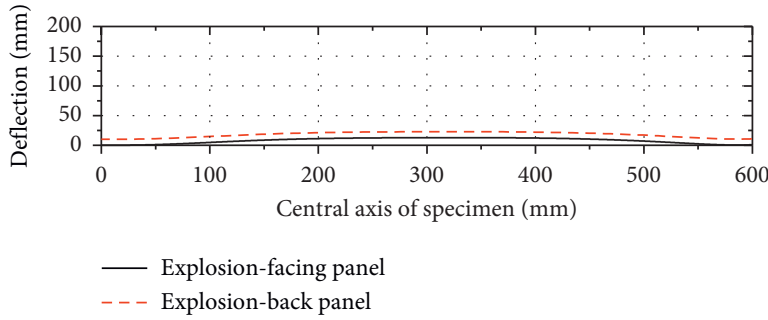

(b)

FIGURE 15: Side deformation and deflection of ST2. (a) Side view of ST2 deformation. (b) ST2 deflection data curve.

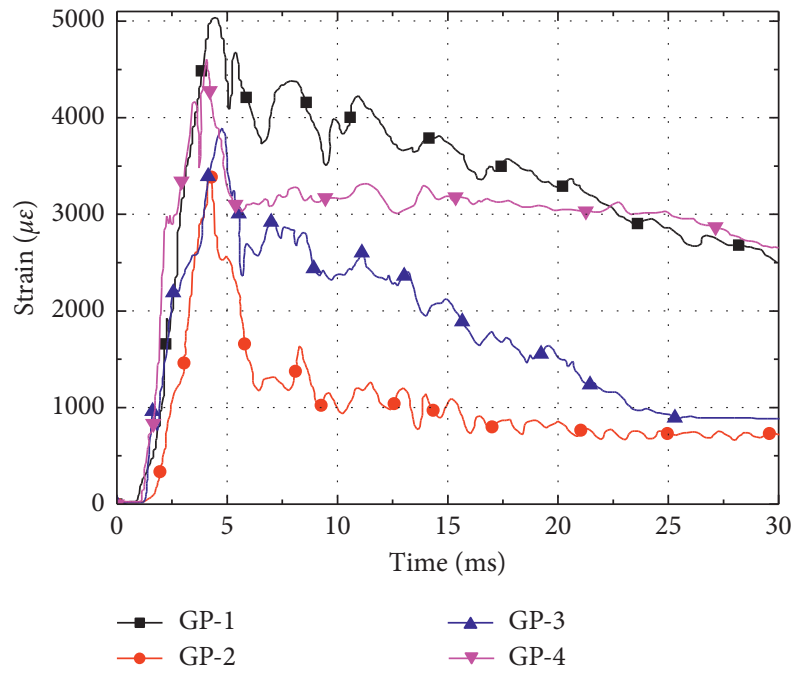

FIGURE 16: Strain time-history curves of ST2 collection points.

\section{Numerical Simulation}

In numerical simulation, when it comes to large amount of model units and complex model, the model needs to be equivalently homogenized. Aktay et al. [17] used the equivalent homogenization numerical simulation technology to simulate the transverse crushing behavior of aluminum honeycombs. This technology can simulate not only the crushing behavior of aluminum honeycomb with different units and wall thickness but also the large-scale crushing failure of aluminum honeycombs. Singh [18] conducted a three-point bending test simulation on aluminum honeycomb plate and compared the actual model with the equivalent homogenization model. It was found that the equivalent homogenization model could not only simulate the deformation failure of aluminum honeycomb plate but also save the calculation time: it took 48 hours for actual model to calculate but only 18 minutes for equivalent homogenization model.

In this paper, the sandwich equivalent method is adopted to simulate the biomimetic layered honeycomb structure. The sandwich equivalent method is to be equivalent to the honeycomb structure. Regarding the outer panel as an isotropic surface layer, the equivalent method can reflect the structural characteristics more truly and more accurately $[19,20]$. The equivalent elastic modulus $E_{\text {eq }}$ and equivalent density $\rho_{\text {eq }}$ of honeycomb structure modified by sandwich equivalent method are as shown in formulas (5) and (6), respectively:

$$
\begin{aligned}
& E_{\text {eq }}=\frac{8 \sqrt{3}}{9} \frac{t}{l} E_{\mathrm{a}}, \\
& \rho_{\text {eq }}=\frac{2 l t}{A_{\mathrm{h}}} \rho_{\mathrm{a}}=\frac{2 l t}{3 \sqrt{3} l^{2} / 4} \rho_{\mathrm{a}}=\frac{8 \sqrt{3}}{9} \frac{t}{l} \rho_{\mathrm{a}},
\end{aligned}
$$

where $t$ is the thickness of honeycomb material, $l$ is the edge length of honeycomb cell, $E_{\mathrm{a}}$ is the elastic modulus of honeycomb material, $A_{\mathrm{h}}$ is the area surrounded by the central point of three adjacent honeycomb cells, and $\rho_{\mathrm{a}}$ is the density of honeycomb material. 


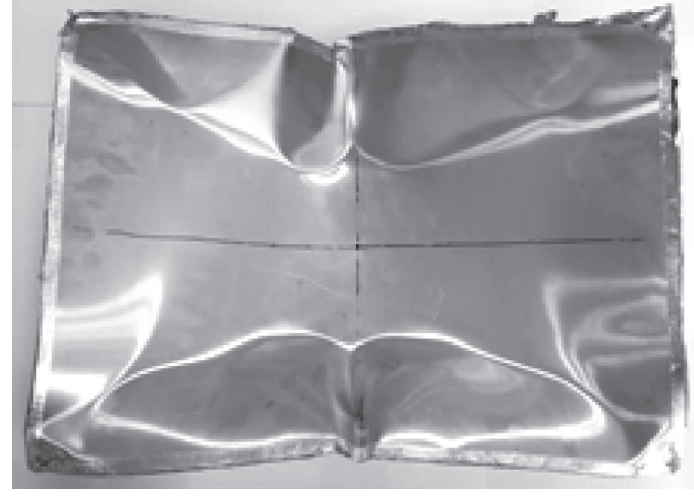

(a)

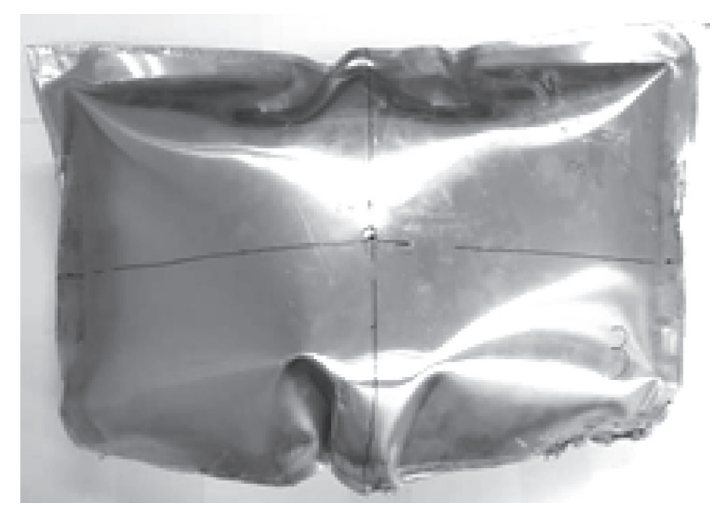

(b)

Figure 17: Front view of ST3 deformation. (a) Explosion-facing panel. (b) Explosion-back panel.

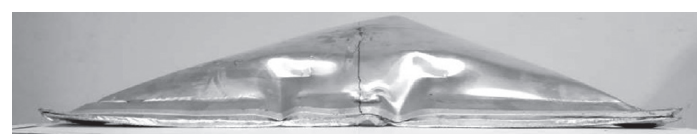

(a)

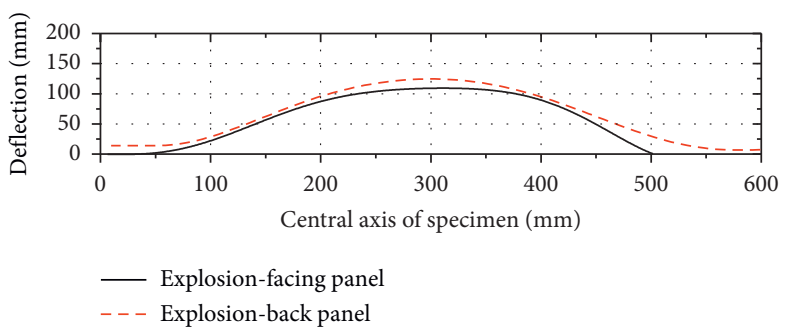

(b)

FIgURE 18: Side deformation and deflection of ST3. (a) Side view of ST3 deformation. (b) ST3 deflection data curve.

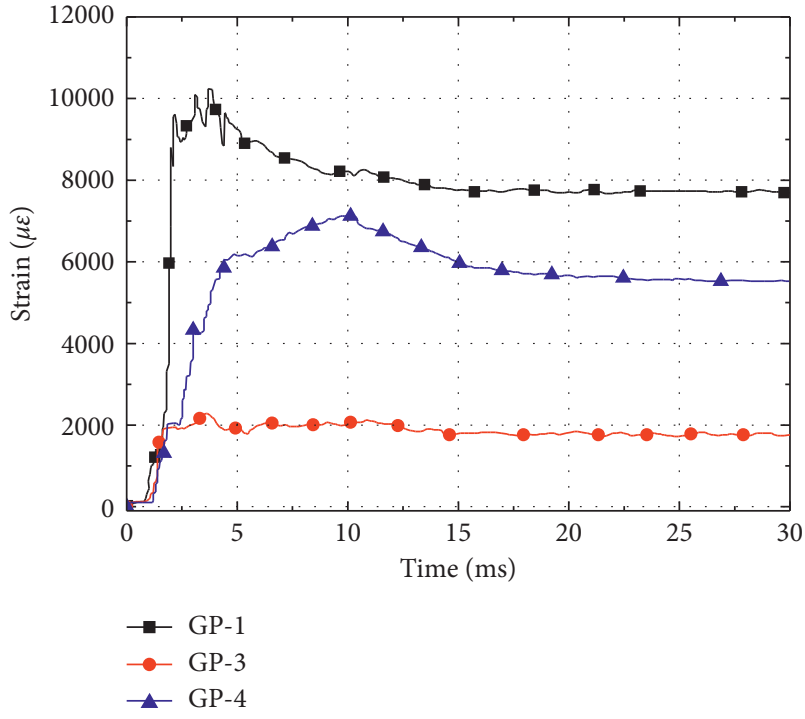

FIGURE 19: Strain time-history curve of ST3 collection point.

As concluded from formulas (5) and (6), the equivalent elastic modulus of honeycomb structure is proportional to its equivalent density.

5.1. Material Model and Parameters. Considering the mechanical response of the honeycomb part of ST1 and ST3 at different strain rates, the material model
MAT_MODIFIED_CRUSHABLE_FOAM is selected, which increases damping effect and strain rate effect on the basis of the material model MAT_CRUSHABLE_FOAM. The constitutive definition of material model MAT_MODIFIED_CRUSHABLE_FOAM taking strain rate effect into consideration is shown in Figure 23.

For the honeycomb part of ST1, according to formulas (5) and (6), its equivalent elastic modulus $E_{\mathrm{eq}}$ is $1212.44 \mathrm{MPa}$, and equivalent density $\rho_{\mathrm{eq}}$ is $48.04 \mathrm{~kg} / \mathrm{m}^{3}$. For the honeycomb part of ST3, its equivalent elastic modulus $E_{\text {eq }}$ is $1.97 \mathrm{MPa}$, and equivalent density $\rho_{\text {eq }}$ is $36.03 \mathrm{~kg} / \mathrm{m}^{3}$.

A static compression test is carried out on the enhanced honeycomb part of ST2, and its constitutive curve is shown in Figure 24. It is observed that the honeycomb enters into an approximate linear constitutive relation after elastic deformation. Under the same stress, the strain in ST2 is negligible compared with the strain in ST3. Therefore, the enhanced honeycomb part of ST2 is simulated by the material model MAT_CRUSHABLE_FOAM, with an equivalent elastic modulus of $2350.56 \mathrm{MPa}$ and an equivalent density of $1778.04 \mathrm{~kg} / \mathrm{m}^{3}$. The honeycomb part of ST4 takes that of ST2 and ST3 as reference.

Material model MAT_PLASTIC_KINEMATIC is used for the explosion-facing panel, the explosion-back panel, and the partition board between sacrificial layer and bearing layer. Material parameters are shown in Table 2.

5.2. Unit and Part. SOLID164 unit is used in the unit of biomimetic layered honeycomb structure, and PART is 


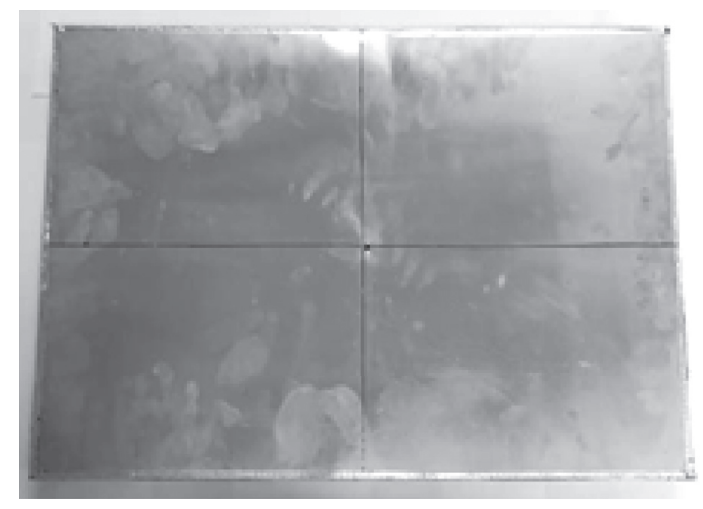

(a)

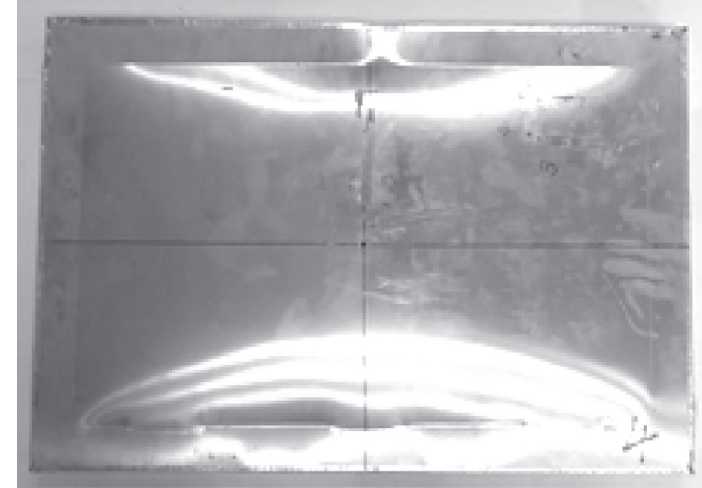

(b)

Figure 20: Front view of ST4 deformation situation. (a) Explosion-facing panel. (b) Explosion-back panel.

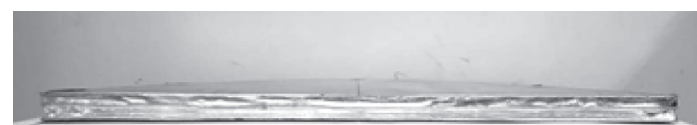

(a)

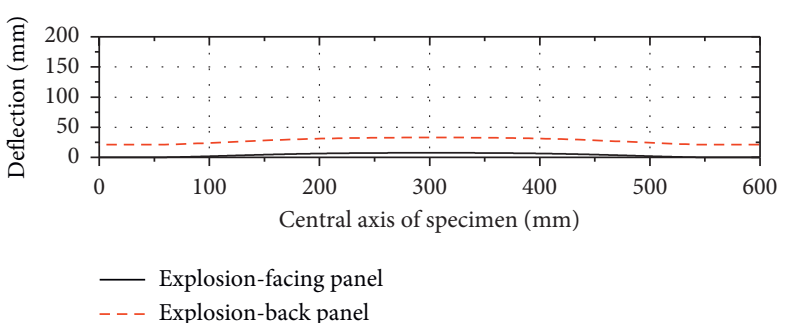

(b)

FIgURE 21: Side deformation and deflection of ST4. (a) Side view of ST4 deformation situation. (b) ST4 deflection data curve.

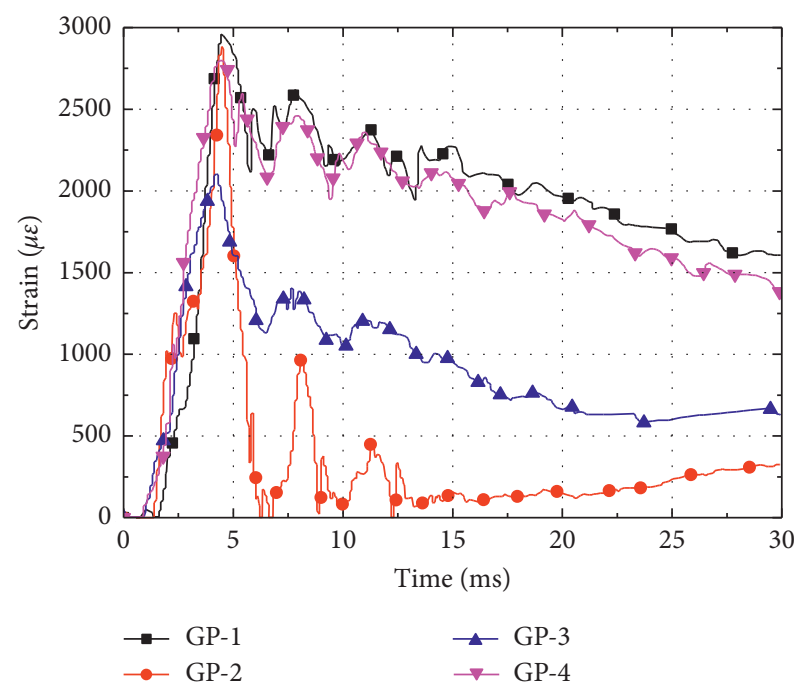

FIgURE 22: Strain time-history curve of ST4 collection point.

defined for explosion-facing panel, partition board, explosion-back panel, sacrificial layer, bearing layer, and so forth, respectively.

5.3. Load and Boundary Condition. The explosion load is applied to the explosion-facing panel by selecting the LOAD_SEGMENT_SET keyword. The load area of explosion-facing panel is defined by SET_SEGMENT, and the

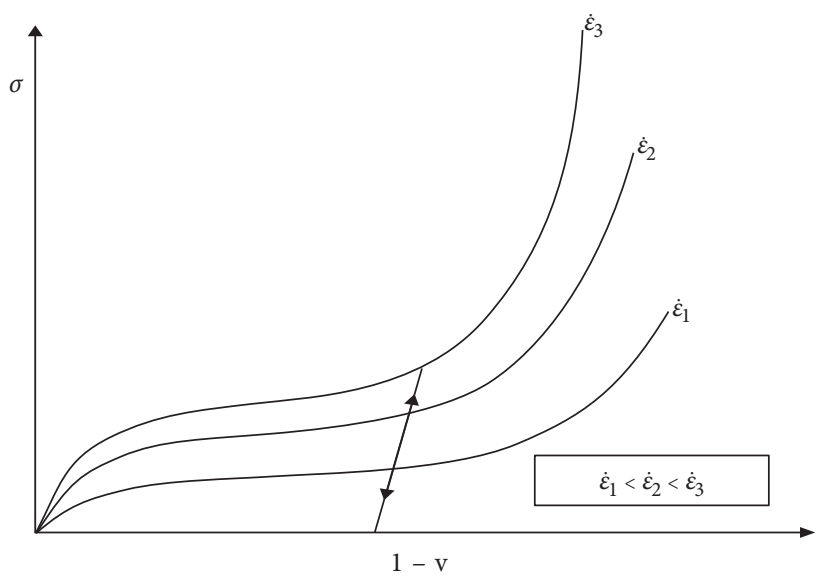

FIGURE 23: Constitutive principle of MAT_MODIFIED_CRUSH ABLE_FOAM.

load time-history curve is defined by DEFINE_CURVE. The 1/4 finite element model is shown in Figure 25. Select the CONTACT_AUTOMATIC_SURFACE_TO_SURFACE

keyword to define the contact, and set the static friction coefficient as 0.61 and the dynamic friction coefficient as 0.47 .

5.4. Results Analysis on Numerical Simulation. Taking strain time-history curve of GP-1 as an example and comparing GP-1 with corresponding NSP-1 (NSP on behalf of 


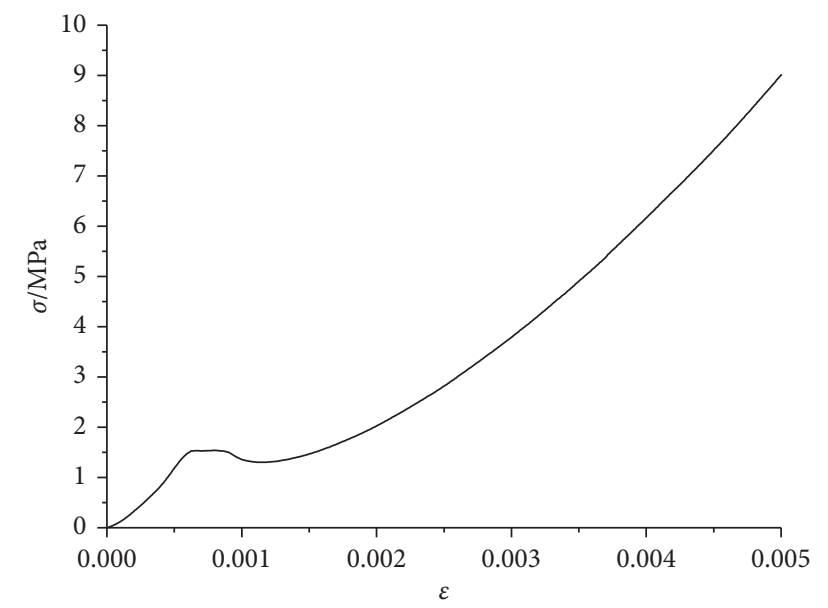

FIgURE 24: Constitutive curve of enhanced honeycomb structure.

TABLE 2: Parameter values of material model MAT_PLASTIC_KINEMATIC.

\begin{tabular}{lc}
\hline Material parameters & Value \\
\hline Density $\rho_{\mathrm{s}}\left(\mathrm{g} / \mathrm{cm}^{3}\right)$ & 2.68 \\
Modulus of elasticity $E_{\mathrm{e}}(\mathrm{GPa})$ & 70.3 \\
Tangent modulus $E_{\mathrm{t}}(\mathrm{GPa})$ & 7.1 \\
Poisson's ratio $v_{\mathrm{s}}$ & 0.33 \\
Yield strength $\sigma_{\mathrm{y}}(\mathrm{MPa})$ & 193 \\
Ultimate strength $\sigma_{\mu}(\mathrm{MPa})$ & 228 \\
\hline
\end{tabular}

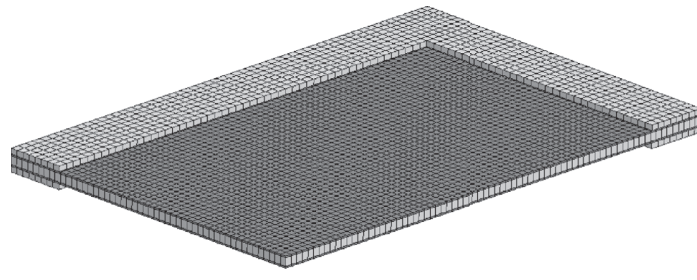

(a)

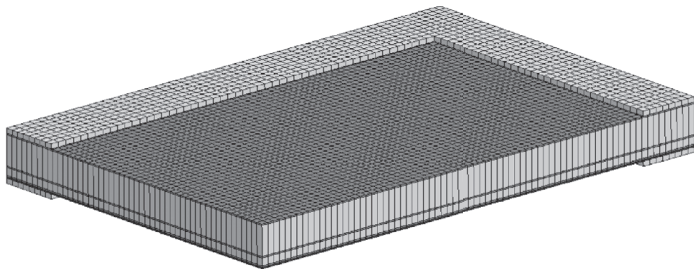

(b)

Figure 25: 1/4 finite element model. (a) ST1 and ST2. (b) ST4 (including ST3).

Numerical Simulation Point) in numerical simulation, it was found from Figure 26 that GP-1 coincides well with the strain time-history curve of the corresponding NSP-1, the peak strain in the curve has a small relative error, and the rise and fall of the curve are close. It is shown that numerical simulation can better reflect the strain time-history law of the collection points in the test and that numerical simulation is feasible.

Then, the failure and deformation of specimen are analyzed after numerical simulation. Taking the working condition of ST3 under the action of explosion as an example, as shown in Figure 27, ST3, as a sacrificial layer structure, has obvious plastic deformation when subjected to explosion loading, which is in coincidence with the experimental result. Compared with the experiment, there also exists fold deformation at the upper and lower edges of ST3 in numerical simulation, and the final failure state of ST3 is "arch" as a whole.
Based on the comparison of the failure and deformation of the specimens mentioned above and the analysis of coincidence degree of the strain time-history curve, it is proven that numerical simulation method is feasible. The internal energy time-history curve and kinetic energy time-history curve of biomimetic layered honeycomb structure ST4 are further obtained through this method as shown in Figure 28. By observing the simulated internal energy time-history curve of ST4, as shown in Figure 28(a), it is concluded that, in the process of explosion-resistance, the energy is mainly absorbed by sacrificial layer, and part of the energy is absorbed by bearing layer, yet the explosion-facing panel, explosion-back panel, and partition board only absorb very little energy. Plus, the total amount of energy absorbed by sacrificial layer is greater than the sum of other parts. Figure 28(b) shows that the peak kinetic energy of different components of biomimetic layered honeycomb structure appears at different times seen through the kinetic energy 


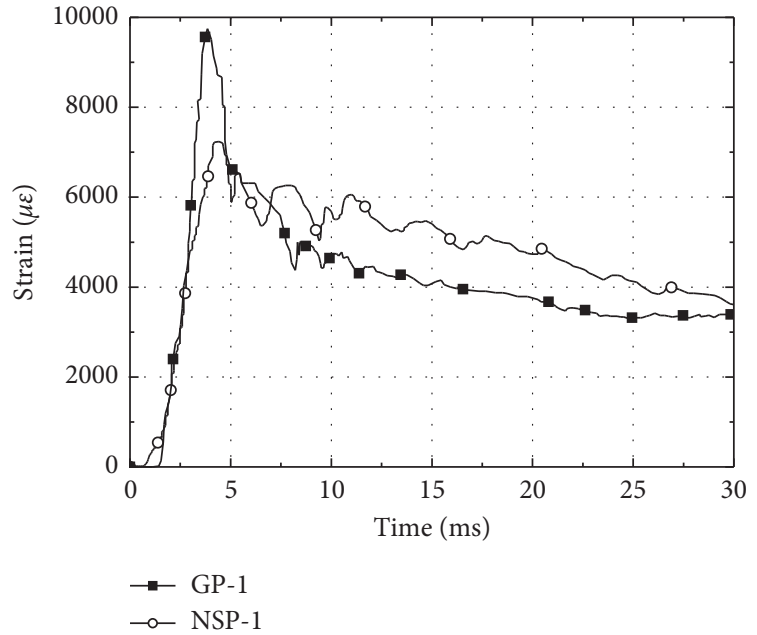

(a)
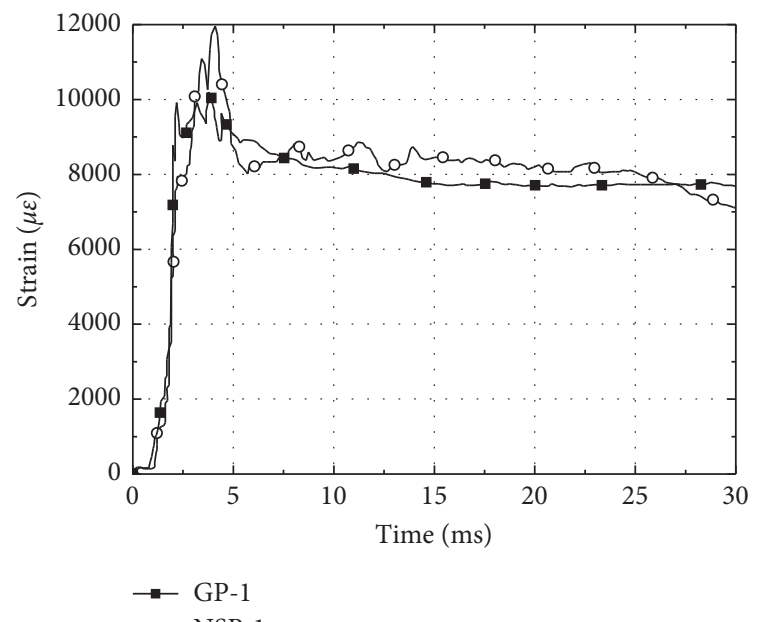

$\rightarrow$ NSP-1

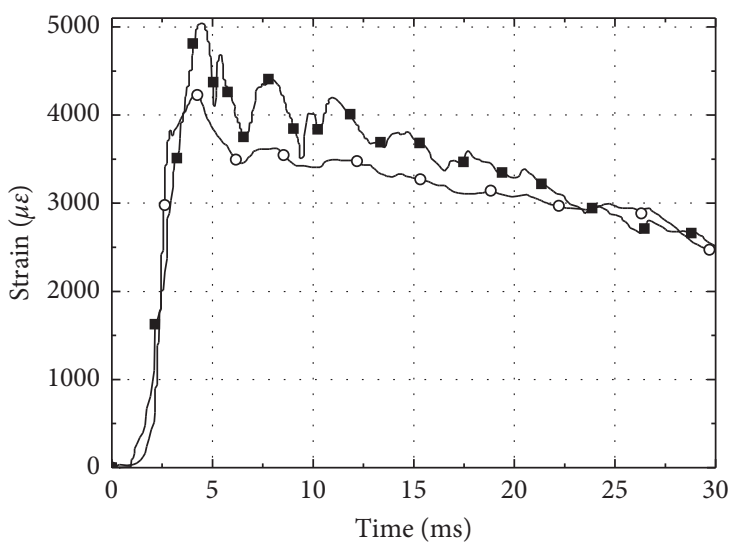

- GP-1

$\rightarrow$ NSP-1

(b)

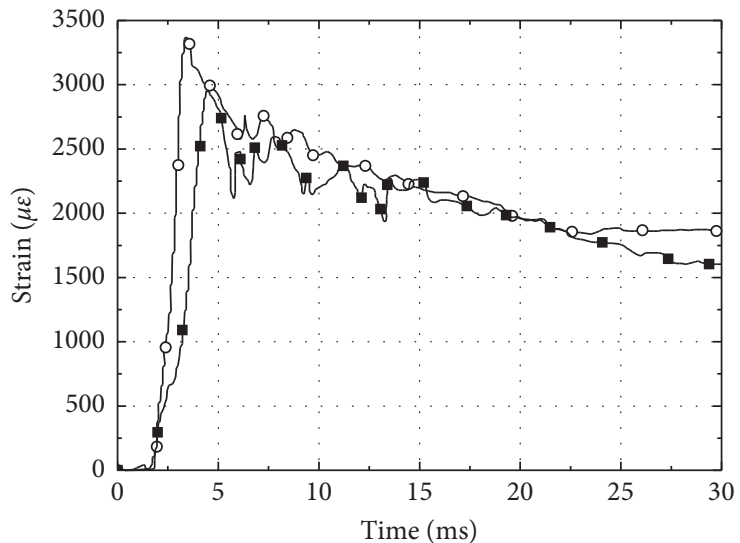

$\rightarrow$ GP-1

$\multimap$ NSP-1

(c)

(d)

FIGURE 26: Comparison of strain time-history curves between experiment and numerical simulation of GP-1 at collection points under four working conditions. (a) ST1. (b) ST2. (c) ST3. (d) ST4.

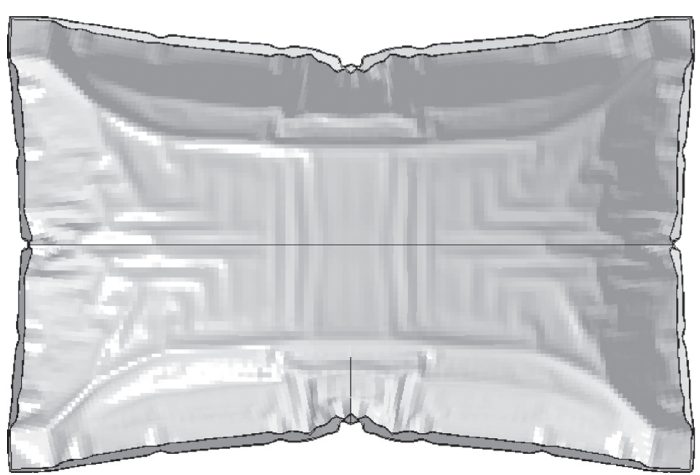

(a)

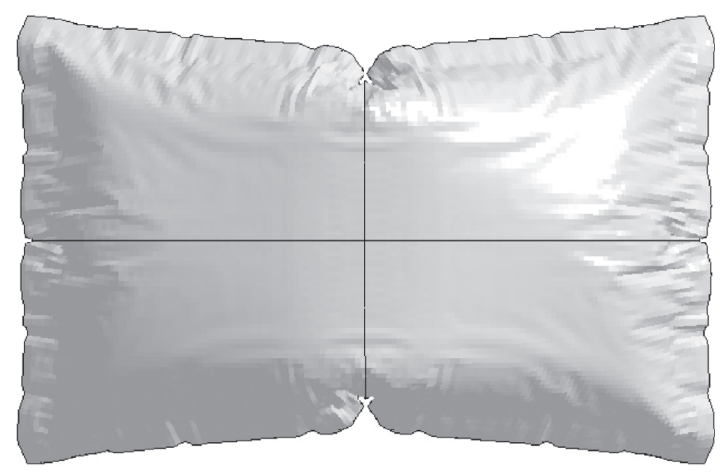

(b)

FIGURE 27: Deformation of ST3 in numerical simulation. (a) Explosion-facing panel in numerical simulation. (b) Explosion-back panel in numerical simulation. 


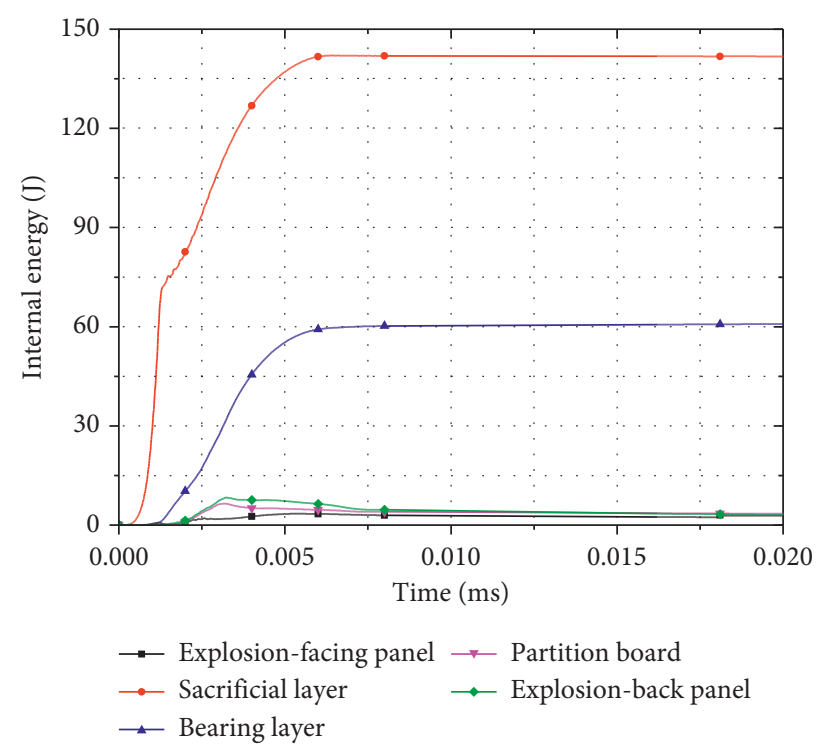

(a)

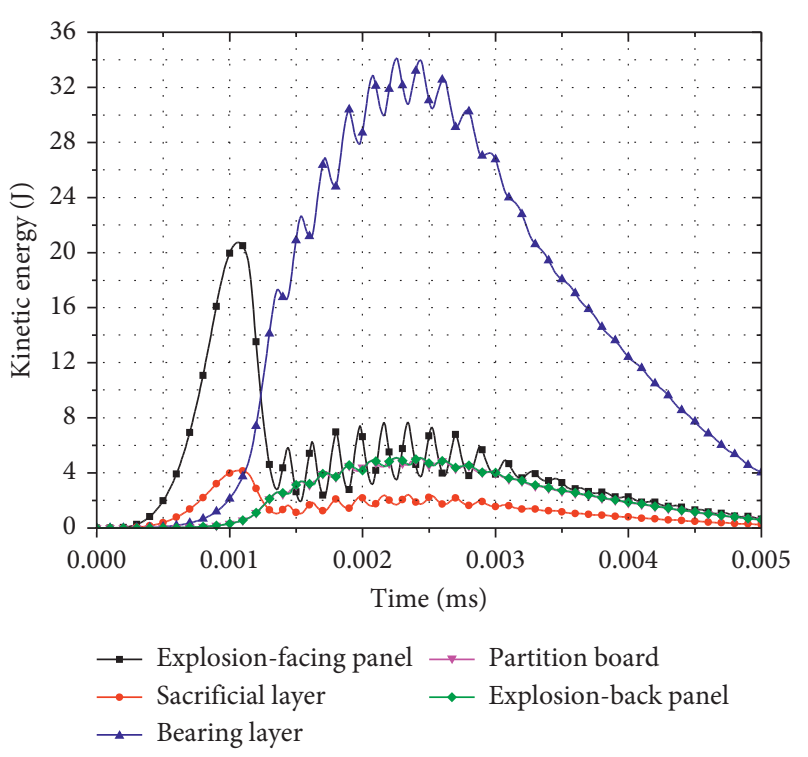

(b)

FIGURE 28: Energy time-history curve of ST4 in numerical simulation. (a) Internal energy time-history curve. (b) Kinetic energy time-history curve.

time-history curve. The explosion-facing panel and sacrificial layer first appear the peak of kinetic energy, followed by the bearing layer, partition board, and explosion-back panel. This is because the compressive deformation of sacrificial layer prolongs the action time of explosion load and thus causes time difference. The reason why the kinetic energy of the bearing layer changes greatly is that the mass of bearing layer is the largest after the filled sand is strengthened.

\section{Conclusion}

Explosion tests of shock tube were carried out on the biomimetic layered honeycomb structure to study its explosionresistant property. As a comparison, the same tests were also conducted on the single-layer honeycomb structure, the sacrificial layer structure, and the bearing layer structure. Based on the homogenization equivalence theory, numerical simulation on the test condition was analyzed. In addition, a comparative analysis on failure deformation between test and numerical simulation was conducted in addition to a coincidence analysis on strain time-history curve between these two as well. The feasibility and effectiveness of numerical simulation method were thus verified.

(1) The experimental results show that the relative error of the incident pressure of explosion shock wave under the four test conditions is small, among which the maximum relative error is only $1.69 \%$. The shock wave propagating in shock tube has the general characteristics of explosive shock wave, that is, containing positive pressure stage and negative pressure stage

(2) The single-layer honeycomb structure has severe deformation under the action of explosion load, its internal honeycomb structure is seriously damaged, and the maximum deflection of its backplane is $78 \mathrm{~mm}$. The bearing layer structure is strengthened by filling sand, and it has light deformation under the action of explosion load, which can be used as the bearing part of the biomimetic layered honeycomb structure. The sacrificial layer structure has the characteristics of layered and staggered arrangement. It has good energy absorption ability and strong toughness under the action of explosion load, and the maximum deflection of its backplane is $125 \mathrm{~mm}$. The biomimetic layered honeycomb structure reveals good overall performance under the action of explosion load and has the ability to withstand multiple explosion loads

(3) The experimental results are in good coincidence with numerical simulation results, and the numerical simulation better restores the strain time-history variation law of the test, which proves that the numerical simulation method on the basis of equivalent homogenization theory is feasible and effective. The numerical simulation shows that, under the action of explosion load, the biomimetic layered honeycomb structure mainly relies on the sacrificial layer to absorb energy, and the structural energy absorption is positively correlated with the degree of structural deformation. At the same time, the kinetic energy variation of the components of biomimetic layered honeycomb structure is proportional to their respective masses

(4) Single-layer honeycomb structure is not suitable to be used as explosion-resistant structure. The bearing layer structure can be used as the bearing part of the biomimetic layered honeycomb structure. The sacrificial layer structure has good energy absorption 
performance, so it can be used as an important part in explosion-resistant structure. In conclusion, taking sacrificial layer structure and bearing layer structure as its main body, the biomimetic layered honeycomb structure has good explosion-resistant performance, so it should be given priority in engineering application

\section{Data Availability}

The data that support the findings of this study are available from the corresponding author upon request.

\section{Conflicts of Interest}

The authors declare that they have no conflicts of interest.

\section{References}

[1] Z. Wang, Y. Zhou, X. Wang et al., "Multi-objective optimization design of a multi-layer honeycomb sandwich structure under blast loading," Proceedings of the Institution of $\mathrm{Me}$ chanical Engineers, Part D: Journal of Automobile Engineering, vol. 231, no. 10, pp. 1449-1458, 2017.

[2] S. Li, X. Li, Z. Wang, G. Wu, G. Lu, and L. Zhao, "Finite element analysis of sandwich panels with stepwise graded aluminum honeycomb cores under blast loading," Composites Part A: Applied Science and Manufacturing, vol. 80, pp. 1-12, 2016.

[3] K. P. Dharmasena, H. N. G. Wadley, Z. Xue, and J. W. Hutchinson, "Mechanical response of metallic honeycomb sandwich panel structures to high-intensity dynamic loading," International Journal of Impact Engineering, vol. 35, no. 9, pp. 1063-1074, 2008.

[4] L. Deng, A. W. Wang, and L. W. Mao, "Energy absorption characteristics of a square hole honeycomb sandwich plate under blast loading," Journal of Vibration and Shock, vol. 319, no. 17, pp. 186-189, 2012.

[5] S. Yang, S. Feng, and S. Y. Wang, "Instability of aluminum honeycomb sandwich panel under blast loading," Chinese Journal of High Pressure Physics, vol. 31, no. 2, pp. 193-201, 2017.

[6] G. N. Nurick, G. S. Langdon, Y. Chi, and N. Jacob, "Behaviour of sandwich panels subjected to intense air blast-part 1: experiments," Composite Structures, vol. 91, no. 4, pp. 433441, 2009.

[7] D. Karagiozova, G. N. Nurick, and G. S. Langdon, "Behaviour of sandwich panels subject to intense air blasts-part 2: numerical simulation," Composite Structures, vol. 91, no. 4, pp. 442-450, 2009.

[8] J. Shen, G. Lu, Z. Wang, and L. Zhao, "Experiments on curved sandwich panels under blast loading," International Journal of Impact Engineering, vol. 37, no. 9, pp. 960-970, 2010.

[9] X. H. Zhang, Z. H. Wang, and L. M. Zhao, "Dynamic responses of sandwich plates with aluminum honeycomb cores subjected to blast loading," Explosion and Shock Waves, vol. 29, no. 4, pp. 356-360, 2009.

[10] X. H. Zhang, Z. H. Wang, and L. M. Zhao, "Dynamic plastic response of sandwich plate with aluminum honeycombs core under blast loading," Chinese Journal of Applied Mechanics, vol. 26, no. 2, pp. 259-263, 2009.

[11] X. Li, P. Zhang, and Z. Wang, "Dynamic behavior of aluminum honeycomb sandwich panels under air blast: experiment and numerical analysis," Composite Structures, vol. 108, no. 1, pp. 1001-1008, 2014.

[12] H. Zhao and W. Liang, "A novel comby scaffold with improved mechanical strength for bone tissue engineering," Materials Letters, vol. 194, pp. 220-223, 2017.

[13] P. Hao and J. Du, "Energy absorption characteristics of bioinspired honeycomb column thin-walled structure under impact loading," Journal of the Mechanical Behavior of Biomedical Materials, vol. 79, pp. 301-308, 2018.

[14] J. Xiang and J. Du, "Energy absorption characteristics of bioinspired honeycomb structure under axial impact loading," Materials Science and Engineering: A, vol. 696, pp. 283-289, 2017.

[15] S. Palanivelu, W. Van Paepegem, J. Degrieck et al., "Closerange blast loading on empty recyclable metal beverage cans for use in sacrificial cladding structure," Engineering Structures, vol. 33, no. 6, pp. 1966-1987, 2011.

[16] Y. Sun, Z. Yu, Z. Wang, and X. Liu, "Novel protective covering to enhance concrete resistance against projectile impact," Construction and Building Materials, vol. 96, pp. 484-490, 2015.

[17] L. Aktay, A. F. Johnson, and B.-H. Kröplin, "Numerical modelling of honeycomb core crush behaviour," Engineering Fracture Mechanics, vol. 75, no. 9, pp. 2616-2630, 2008.

[18] A. K. Singh, Blast Mitigation Studies for All Metal Plate and Honeycomb Sandwich Panels, The Pennsylvania State University, Pennsylvania, USA, 2012.

[19] D. Jiang, S. Q. Wu, Q. G. Fei et al., "Parameter identification approach of honeycomb sandwich composite with uncertainties," Journal of Vibration and Shock, vol. 34, no. 2, pp. 14-19, 2015.

[20] T. L. Zhang, Y. L. Ding, and H. B. Jin, "Comparative analysis of equivalent models for honeycomb sandwich plates," Chinese Journal of Applied Mechanics, vol. 28, no. 3, pp. 275-282, 2011. 